University of Nebraska - Lincoln

DigitalCommons@University of Nebraska - Lincoln

9-1992

\title{
Aggressive Motivation in the Midas Cichlid: Evidence for Behavioral Efference
}

Alan B. Bond

University of Nebraska - Lincoln, abond1@unl.edu

Follow this and additional works at: https://digitalcommons.unl.edu/bioscibehavior

Part of the Behavior and Ethology Commons

Bond, Alan B., "Aggressive Motivation in the Midas Cichlid: Evidence for Behavioral Efference" (1992). Papers in Behavior and Biological Sciences. 68.

https://digitalcommons.unl.edu/bioscibehavior/68

This Article is brought to you for free and open access by the Papers in the Biological Sciences at DigitalCommons@University of Nebraska - Lincoln. It has been accepted for inclusion in Papers in Behavior and Biological Sciences by an authorized administrator of DigitalCommons@University of Nebraska - Lincoln. 
Published in Behaviour 122:3/4 (September 1992), pp. 135-152.

Published by E. J. Brill, Leiden. Used by permission.

I am deeply obliged to G. W. Barlow for allowing me to conduct yet one more analysis of his cichlid aggression data set. I also thank G. W. Barlow and W. Rogers for their comments and criticisms of the manuscript.

\title{
Aggressive Motivation in the Midas Cichlid: Evidence for Behavioral Efference
}

\author{
Alan B. Bond \\ University of Nebraska State Museum, W436 Nebraska Hall, Lincoln, NE 68588-0514, USA
}

\begin{abstract}
Behavioral Efference is a hypothetical positive feedback from the performance of an aggressive display that augments the level of aggressive motivation. The hypothesis was proposed (Bond, 1989) to account for the occurrence of truthful communication during aggressive encounters, even in the face of a presumed selective pressure in favor of deceit (Maynard Smith, 1984). Evidence of Behavioral Efference was sought in an experimental study of adult Midas cichlids Cichlasoma citrinellum, in which subjects responded aggressively to varying sizes of dummy fish. Before and after each aggression trial, the level of aggressive motivation was estimated from the intensity of the subject's attacks on conspecific juveniles. A weighted index of aggressiveness that objectively combined the frequencies of four aggressive action patterns was obtained using detrended correspondence analysis. Aggression indices from aggression trials, as well as from intertrial intervals, furnished a basis for comparison of two causal models: behavioral efference, which assumes that post-stimulus motivation is substantially influenced by display performance, and Direct Stimulus Mediation, which assumes that the displays themselves play no immediate causal role. When the subjects actively displayed to the stimulus dummy, the results showed no significant correlation between the size of the dummy and the magnitude of the motivational effect. However, a significant relationship was demonstrated between the level of aggressive display and subsequent increases in aggressive motivation, in precise accord with the Behavioral Efference model. Direct Stimulus Mediation was evident only in trials in which the subject displayed no overt aggression toward the stimulus object. An account of the functional significance of Behavioral Efference is provided, suggesting that the feedback serves to regulate the intensity of aggressive interactions by preparing the displaying individual for active combat.
\end{abstract}

\section{Introduction}

Aggressive behavior in many species does not consist of a single action pattern produced at a typical intensity. Instead, the animal performs 
a variety of distinctive displays, each of which is associated with a characteristic probability of subsequent attack or withdrawal (Tinbergen, 1959; Lorenz, 1966). The form and frequency of an individual's behavior, thus, provides reliable information about its level of aggressive motivation. This association between display and motivation has traditionally been viewed as the result of selection for truthful communication: The action patterns that characterize a particular motivational level are presumed to have evolved as a means of informing an opponent about the displaying animal's motivational state (Tinbergen, 1959).

Maynard Smith (1984) has argued that this interpretation of the motivational basis of aggressive displays directly conflicts with the presumed selective advantage of aggressive behavior. Simply stated, if the function of aggressive displays is to resolve a conflict over resources, and if the more aggressive individual will win a disproportionate share of such conflicts, it is not clear why it should ever be adaptive to display a motivational level that is lower than that of one's opponent (Maynard Smith, 1984). On the other hand, if an animal's aggressive behavior does not accurately reflect an individual's motivation or intentions, it is difficult to understand why complex, graded displays should ever have evolved, why aggression is not always displayed with typical intensity (Dawkins \& Krebs, 1978).

One approach to resolving this paradox is to consider aggressive display as not just a product of a particular motivational level, but as one component of a causal complex that includes both efferent and afferent paths of influence. If there is a causal linkage between performance and motivation, displays will be partly responsible for generating the current level of aggressive motivation, and will, therefore, necessarily be truthful. The Behavioral Efference Hypothesis asserts that, while higher levels of aggressive motivation may cause the animal to produce more intense displays, there is also a positive feedback from performance of a display that increases aggressive motivation (Bond, 1989).

The conviction that behavior may have both facilitative and inhibitive central effects has a respectable history in ethology (Hinde, 1970; McFarland, 1971). Direct experimental evidence of a positive feedback of performance on motivation is fairly uncommon in the ethological literature, however. There are some data available from studies of courtship behavior, in which the stimulatory or potentiating effects of display performance have long been recognized (Morris, 1956). For example, Nelson (1964) and Hinde (1958) were able to infer self-facilitation in the performance of courtship and territorial displays through analysis of sequential patterning. In a particularly elegant experiment, Wilz (1970) was able to 
show that performance of the "creeping through" display by male sticklebacks was instrumental in switching their own predisposition from aggression to courtship.

The paucity of similar studies on the facilitative effects of aggressive displays suggests that they may have simply not been looked for. Studies of aggressive priming (e.g. Hogan \& Roper, 1978; Hogan \& Bols, 1980) have generally not attempted to separate the motivational effects of exposure to the priming stimulus from those of the subsequent performance of aggressive displays. The traditional ethological view of behavior as being "released" by an appropriate stimulus (Lorenz, 1950) may have served to focus primary attention on the role of the stimulus, rather than the response, in aggression. Indirect evidence of Behavioral Efference in aggression can, however, be adduced from a variety of different sources, including studies of human facial expression, of aggressive catharsis, and of the operant conditioning of aggressive behavior (Bond, 1989).

There is substantial literature, dating back to Darwin (1872), contending that the intensity of emotional experience in humans is directly affected by their own facial expressions (Ekman et al., 1983; Zajonc, 1985; Collier, 1985), and the existence of this "facial efference" has been substantiated in several laboratory studies (Laird, 1984). In addition, it has been shown for a number of species that the opportunity to engage in aggressive displays can serve as a reinforcer in operant conditioning paradigms (Hogan \& Roper, 1978; Huntingford \& Tuner, 1987). If aggression is reinforcing for an arbitrary operant, it seems reasonable to argue that it should be self-reinforcing under circumstances of free elicitation (Baenninger, 1974; Potegal, 1979). Finally, studies designed to test for the hypothetical cathartic effects of aggression (Lorenz, 1966) have generally found that aggressive behavior "leads to increased, rather than decreased hostility on postaggression measures" (Quanty, 1976), a result consistent with positive behavioral efference.

Although these lines of evidence are suggestive, they are fairly indirect. The existence of positive feedback from the performance of aggressive displays seems never to have been explicitly tested in animals. A strong inference of causality in this case would require neurophysiological intervention to control either motivation or display as an independent variable (Bond, 1989). But if efference is a robust effect, any study that directly manipulates aggressive motivation should provide at least correlational evidence that is consistent with the hypothesis. Perhaps the most compelling and attractive of such correlational designs was developed by Heiligenberg $(1965,1976)$ and Leong $(1969)$ to investigate stimulus effects on aggressive arousal in cichlid fish. 
The Heiligenberg approach is essentially a pre-test/post-test contrast. A territorial adult fish is placed in a tank with a group of conspecific juveniles. The juveniles are blinded to prevent them from responding to the adult's actions, but their presence still supplies a tonic, low-level aggressive stimulus. The level of aggression toward the juveniles provides a measure of the motivational level of the subject fish (Heiligenberg, 1976). The intervention consists of a brief exposure to a stimulus object, a dummy painted with some of the characteristic patterns of territorial adults (Heiligenberg, 1965; Leong, 1969). The frequency and intensity of aggression toward the juveniles is assessed before and after stimulus presentation, and the increment in aggression following the stimulus quantifies its motivational effect (Heiligenberg, 1965).

This design can readily be modified for use in the analysis of Behavioral Efference. We simply need to measure the intensity of the subject's aggressive behavior toward the stimulus dummy, as well as to the juveniles in the pre-test and post-test intervals. The effect of the display behavior on the post-test motivation can then be contrasted with that of the magnitude of the aggressive stimulus, using multivariate regression. Barlow replicated Heiligenberg's (1965) experiment, using Midas cichlids, Cichlasoma citrinellum, responding to varying sizes of dummy fish (Barlow et al., 1984). The results were analyzed extensively for evidence of stimulus effects (Barlow et al., 1984; Bond et al., 1985), but the magnitude of the subject's display behavior was never included as a causal variable. In this study, I have reanalyzed Barlow's Midas cichlid data set, explicitly testing for the possibility of behavioral efference.

\section{Materials and methods}

The subject pool consisted of 12 adult Midas cichlids, selected for uniform size (220 to $250 \mathrm{~g}$, 170 to $190 \mathrm{~mm}$ standard length). There were equal numbers of males and females, as well as equal numbers of the two color morphs (gold and gray). To maintain aggressiveness, subjects were primed by regular exposure to novel rivals for at least three weeks prior to the experiment. Experiments were conducted in an observation tank $(90 \times 60 \times 46 \mathrm{~cm}$ deep) that contained one subject and 10 blinded juveniles (about $10 \mathrm{~g}$ each). A more detailed account of the apparatus and treatment conditions is provided in Barlow et al. (1984).

To provide standardized stimuli for aggressive behavior, latex dummies were created from preserved specimens in five standard lengths: 120, 140, 160, 180, and 200 $\mathrm{mm}$, a range of $70 \%$ to $110 \%$ of the size of the median subject. The dummies were suspended from a motor-driven pulley system outside the observation tank and were concealed from the subject until the beginning of a presentation trial. During stimulus presentation, the dummy was drawn slowly into the subject's view, moving parallel to the glass at about $1 \mathrm{~cm} / \mathrm{s}$. It moved out of view after $1 \mathrm{~min}$. 
An experimental session consisted of seven stimulus trials: An initial, baseline control trial, a single presentation trial of each of the five sizes of dummy fish, and a blank control trial. During the blank control, the driver motor was run for $1 \mathrm{~min}$ in the absence of a dummy; during the baseline control, no stimuli of any kind were presented. The seven trials alternated with seven 15-min intertrial intervals. Each subject was given one experimental session per day for six successive days. The baseline control was always the first trial in a session. Otherwise, trial order was randomized across days, with the constraint that all trial types occurred only once in each serial position.

The subject's behavior was recorded continuously for the full duration of each session. An observer, seated behind a blind, entered the behavioral categories manually on a keyboard interfaced with a real-time data acquisition system. Four aggressive action patterns were recorded: Flare, Bite, Butt, and Charge (Barlow et al., 1984; Losey, 1982). Flare involved orienting toward the dummy and extending the gill-covers while the mouth remained closed. Bite entailed open-mouthed contact with one of the juveniles or with the glass that separated the subject from the dummy. Butt was a similar action pattern, but with the mouth closed. Charge constituted an accelerated swim toward the dummy or one of the juveniles.

Virtually all aggressive behavior during presentation trials was directed to the dummy. During control trials, as well as during the intertrial intervals, aggression was directed only to the juveniles. The response measures used were the frequencies per minute of the four action patterns during each 1-min trial period, as well as during 5min segments of intertrial interval immediately prior to and immediately following stimulus presentation. The data set thus consisted of six replicate aggression assays on each of seven trial types for each of 12 subjects, with frequency measures taken before, during, and after each stimulus trial.

\section{Derivation of the aggression index}

The first requirement for the analysis was to derive a single, composite index of aggressiveness, one that combined the information provided in the frequencies of the four action patterns. BARLOW et al. (1984) simply summed across behavior categories to obtain an aggregate frequency measure, but this approach overlooks the additional information presented by the animal's choice of action pattern. More aggressive individuals perform aggressive acts more frequently, but they may also exhibit a different suite of behaviors than do less motivated animals (Tinbergen, 1959; Vodegel, 1978). What is needed is a weighted sum of frequencies, in which the weights represent characteristic values for each action pattern on a scale of increasing aggressiveness.

The most objective approach to assigning weights is through ordination, a class of statistical techniques by which a number of independent variables are reduced to a smaller, conceptually more coherent set of weighted sums. The typical features are illustrated by principal components analysis (PCA), which uses rigid geometric rotation to derive a succession of orthogonal axes, or "principal components." The values of 
the components are redescriptions of the data set in terms of weighted sums of the initial variables. Most of the information present in the original data set is retained in the transformation, since each successive component maximizes the amount of residual variance it accounts for.

PCA is not necessarily the best ordination technique for behavioral data, however, because it implicitly assumes that variables increase or decrease linearly along a component axis. An alternative, more robust, approach is detrended correspondence analysis (DCA), which ordinates the data matrix directly by an iterative averaging process that maximizes the correlation of observations and variables (Gauch, 1982). The results of DCA and PCA are similar when the data set is well-behaved, but DCA makes fewer assumptions about the underlying relationship between variables and component axes. As a result, it is generally superior to other ordination techniques when the samples are very heterogeneous or when the relationship between variables and component axes is not monotonic (Gauch et al., 1977; Hill \& Gauch, 1980).

To derive an aggression index by ordination, I assumed that the first component axis of the responses to the stimulus dummies, which includes the largest proportion of the total variance, should provide the best objective measure of aggressiveness. DCA was performed on the frequencies of the four aggressive action patterns from the full data set of 504 stimulus trials, using the DECORANA program (Hill \& Gauch, 1980). The first DCA axis, which accounted for $51 \%$ of the total variance, yielded ordination scores of 3.30 for Bite, 2.42 for Charge, 1.12 for Butt, and 0.0 for Flare. (The minimum score is set to zero by convention.)

Ordination produces a weighted sum that accounts for a maximum proportion of the underlying variance, but the orientation of the ordination axis with respect to any real-world gradient is entirely arbitrary. Observations with similar mean scores have a similar composition, in terms of the type and diversity of behavior exhibited, but whether a given score indicates high or low levels of aggression cannot be determined by ordination alone. The simplest criterion for orienting the axis seems to be frequency: more aggressive individuals should display aggressive behavior more often. The appropriate orientation of the DCA axis, therefore, should be the one that yields a positive correlation between the mean ordination score for an observation and the aggregate frequency of aggressive behavior.

For the initial set of variable scores, this correlation was -0.47 , indicating that the DCA axis was inverted with respect to frequency. The variable scores were, therefore, reversed to reorient the axis, yielding values of 3.30 for Flare, 2.18 for Butt, 0.88 for Charge, and 0.0 for Bite. Finally, given that the aggression index had to combine the information from 


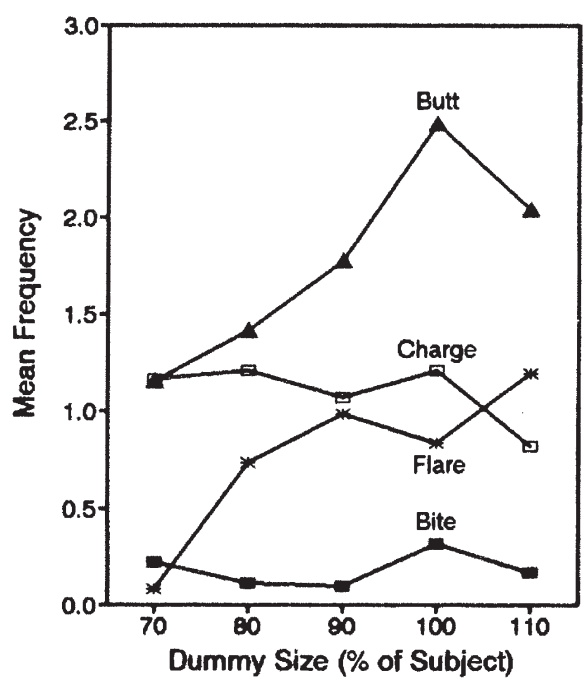

Figure 1. Mean frequency of four aggressive action patterns during the stimulus presentation interval, according to dummy size

both composition and frequency, I added 1.0 to each ordination score to convert them to weights. Aggression indices were computed as weighted sums of act frequencies for the stimulus trials (TRL), as well as the 5-min intervals before (PRE) and after (POST) stimulus presentation. These three dependent variables and the independent variables of dummy size (SIZ) and day of treatment (DAY) formed the basis for all subsequent data analyses.

The DCA scores are not in the rank order that would have been predicted from previous studies (Barlow \& Ballin, 1976; Losey, 1982). In particular, Bite and Chase have generally been considered more aggressive than Flare, which is commonly associated with withdrawal (Losey, 1982). The source of this difference is made apparent in Figure 1, which displays the mean frequency of each of the four action patterns according to the size of the stimulus dummy. Butt and Flare were exhibited more often toward larger dummies than smaller ones, while Charge and Bite were less affected by dummy size. Because ordination techniques assign scores on the basis of the influence of each variable on the aggregate variance of the data set, Butt and Flare were adjudged more sensitive indicators of the intensity of the subject's response. If something other than dummy size had been used to manipulate motivation, we might well have obtained a different configuration of ordination scores. 


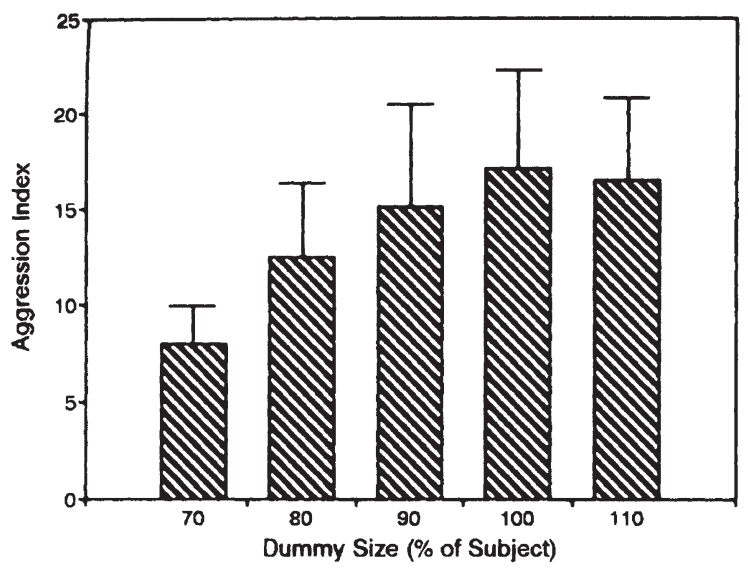

Figure 2. Effect of dummy size (SIZ) on intensity of aggression during the stimulus presentation interval (TRL). Hash marks indicate two standard errors of the mean.

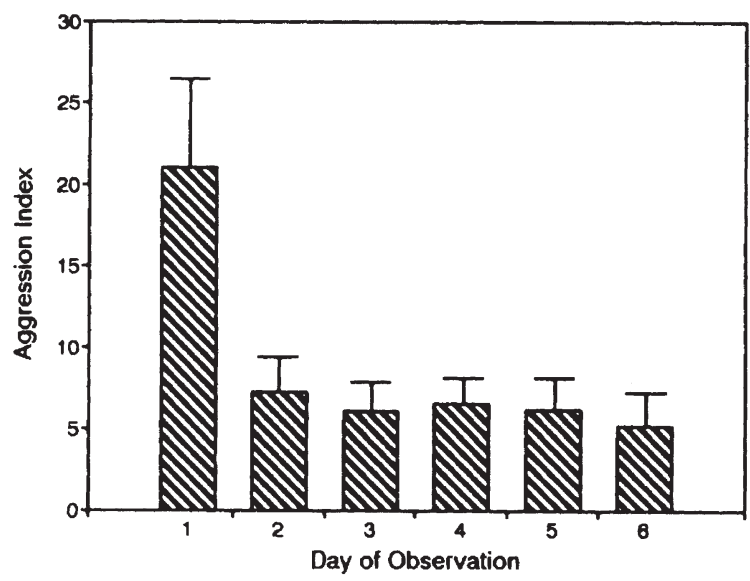

Figure 3. Effect of treatment day (DAY) on intensity of aggression during the stimulus presentation interval (TRL). Hash marks indicate two standard errors of the mean.

To confirm the usefulness of the aggression index, I examined the influence of the independent variables on TRL, the aggressive behavior displayed to the dummy. The two control trial types were discarded, yielding a total sample size of 360: 5 sizes of dummy replicated once a day for 6 days across 12 subjects. Repeated-measures analysis of variance on this data set showed a significant effect on SIZ (F $(4,44)=4.41, p<0.005$; Figure 2$)$ and DAY $(F(5,55)=19.6, p<0.001$; Figure 3$)$, but no significant in- 
teraction $(\mathrm{F}(20,220)=1.26, p>0.2)$. Subject fish clearly responded most aggressively to the larger dummies (Figure 2), and the response to dummies habituated rapidly with repeated exposures (Figure 3). These results are comparable to, but more sensitive than, those of Barlow et al. (1984), confirming that the aggression index provides a believable account of the subject's behavior.

\section{Results}

The critical measure of the motivational effects of stimulus presentation is POST, the level of aggression toward the juveniles in the 5-min interval after the dummy has been removed. In the customary view, which might be termed Direct Stimulus Mediation, POST and TRL are directly and independently affected by SIZ. That is, the magnitude of both the direct response to the dummy and the subsequent motivational impact are an immediate reflection of the magnitude of the aggressive stimulus. Behavioral Efference, on the other hand, posits that POST should be most affected by TRL and only indirect influenced by SIZ. This is because stimulus magnitude will only account for a portion of the variance in aggressive behavior toward the dummy, while all displays performed during stimulus presentation will have an efferent impact on motivation during the post-stimulus interval. To contrast these two hypotheses, we require a statistical technique that controls for the influence of prior motivation (PRE) and quantifies directly the relative importance of SIZ and TRL.

The optimal approach to this analysis is multivariate regression. To display the differentiating features of the hypotheses to be contrasted, I will use a path diagram, a network of vectors that specifies the presumed causal paths among the variables James et al., 1982). The relative importance of each path segment is measured by its path coefficient, $p$, which is equivalent to a standardized regression coefficient from the appropriate multivariate regression analysis.

The path diagram in Figure 4 illustrates the causal relationships postulated by the Behavioral Efference hypothesis. In this model, four of the path segments are drawn with solid lines and reflect true causal influences. The fifth segment, $\mathrm{p}_{01}$, is drawn with a dashed line to indicate that it is a fictitious or artifactual relationship. In the strongest form of the hypothesis, the only influence of dummy size on post-stimulus motivation is indirect, through its effect on display behavior. The model predicts that, when all other relationships are accounted for, $\mathrm{p}_{01}$ will prove to be statistically insignificant. 


\section{Model of Behavioral Efference}

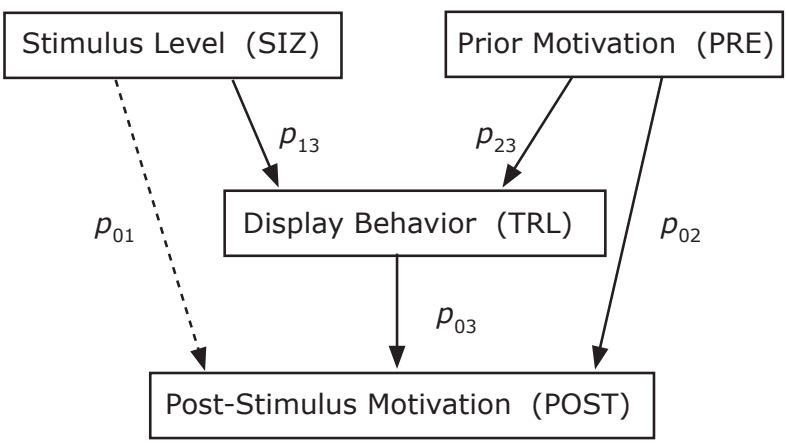

Figure 4. Path analysis diagram, indicating relationships between standardized variables SIZ, PRE, TRL and POST in a multivariate regression, under the assumption of Behavioral Efference. Path coefficients, p, are regression coefficients from TRL $=\mathrm{p}_{13}$ *SIZ $+\mathrm{p}_{23}$ * PRE $+\mathrm{B}$ and from POST $=\mathrm{p}_{01}$ *SIZ $+\mathrm{p}_{02}$ *PRE $+\mathrm{p}_{03}$ * $\mathrm{TRL}+\mathrm{B}$. The path segment shown with a dashed line is hypothesized to be statistically insignificant.

\section{Model of Direct Stimulus Mediation}

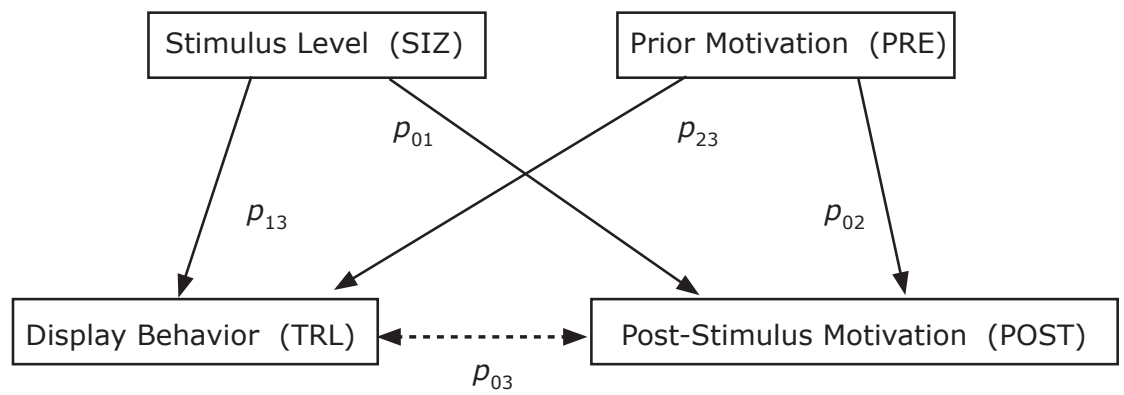

Figure 5. Path analysis diagram, indicating relationships between standardized variables SIZ, PRE, TRL and POST in a multivariate regression, under the classical ethological assumption of Direct Stimulus Mediation. Path coefficients, $p$, are regression coefficients from TRL $=\mathrm{p}_{13}$ *SIZ $+\mathrm{p}_{23}$ * PRE $+\mathrm{B}$ and from POST $+\mathrm{p}_{01}$ * $\mathrm{SIZ}+\mathrm{p}_{02}{ }^{*} \mathrm{PRE}+\mathrm{p}_{03}{ }^{*} \mathrm{TRL}+\mathrm{B}$. The path segment shown with a dashed line is hypothesized to be statistically insignificant.

The alternative model of Direct Stimulus Mediation of motivational effects is diagrammed in Figure 5. In this case, it is the relationship between display behavior and post-stimulus motivation, $\mathrm{p}_{03}$, that is fictitious, a consequence of the joint influence of dummy size and prior 
motivation on both variables. The two causal models thus make distinctive and readily testable predictions about the significance of two of the path segments.

\section{Evidence consistent with Behavioral Efference}

To test these predictions, I began the analysis by deleting all trials in which the subject fish did not respond to the dummy (i.e. TRL was zero). For the remaining sample of 290 trials, the aggression indices were subjected to a log transformation to bring their distributions closer to normality, and all four variables were standardized to a mean of 0 and standard deviation of 1 .

A multivariate regression analysis was conducted, using the model POST $=\mathrm{p}_{01}{ }^{*} \mathrm{SIZ}+\mathrm{p}_{02}{ }^{*}$ PRE $+\mathrm{p}_{03}$ * TRL $+\mathrm{B}(\mathrm{SAS}, 1988)$. The model accounted for $27.0 \%$ of the variance in POST. In a subsequent set of stepwise analyses, each of the possible pairs of the three predictor variables was initially forced to be included in the model. The unique contribution of the third variable in POST was then calculated as the squared semipartial correlation coefficient, and its significance was assessed with an $\mathrm{F}$ test (Tabachnick \& Fidell, 1983).

When the influence of the other predictors was eliminated, both PRE and TRL still evidenced a significant influence on POST. PRE $\left(\mathrm{p}_{02}\right)$ alone accounted for $14.5 \%$ of the variance in POST $(\mathrm{F}(3,286)=56.7, p<$ $0.0001)$, and TRL $\left(\mathrm{p}_{03}\right)$ accounted for another $7.4 \%(\mathrm{~F}(3,286)=2.89, p<$ $0.001)$. SIZ $\left(\mathrm{p}_{01}\right)$, however, showed virtually no unique contribution to POST (less than $0.01 \%$ of the variance: $F(3,286)=0.004, p>0.9)$. These relationships were as predicted by the Behavioral Efference model (Figure 4), and appear to be difficult to reconcile with Direct Stimulus Mediation (Figure 5).

To control for the possible influence of habituation on these results, the analysis was repeated after standardizing each of the aggression measures (PRE, TRL, and POST) to a mean of 0 and a standard deviation of 1 within each DAY of the experiment. This procedure eliminates habituation across days (Figure 3) as a factor in the regression. Under these circumstances, the three predictor variables still accounted for $26.1 \%$ of the variance in POST. PRE alone accounted for $13.8 \%(\mathrm{~F}(3,286)=53.4, p<0.0001)$, while TRL accounted for another $7.7 \%(\mathrm{~F}(3,286)=29.8, p<0.0001)$. And again, SIZ showed no substantial contribution to POST (less than $0.01 \%$ of the variance: $F(3,286)=$ $0.019, p>0.8)$. 
Finally, the analysis was repeated yet again, this time including the size of the dummy presented in the immediately previous trial (PRV) as an additional predictor variable. The addition of a fourth predictor had virtually no effect on the total variance accounted for, increasing it from $27.0 \%$ to $27.6 \%$. PRV did not decrease the significance of the TRL effect, which remained at $7.2 \%$ of the variance $(F(4,285)=28.4, p<0.0001)$, and did not, itself, exhibit a significant influence on POST $(0.6 \%$ of the variance: $F(4,285)=2.42, p>0.1)$.

\section{Evidence consistent with Direct Stimulus Mediation}

The absence of significant effects of SIZ on POST in this analysis must be treated with caution. It does not necessarily indicate that dummy size had no direct influence on post-stimulus motivation. TRL was strongly correlated with SIZ (Figure 2): A multivariate regression using the model TRL $=\mathrm{p}_{13}$ * SIZ $+\mathrm{p}_{23}$ * PRE $+\mathrm{B}$ indicated that $3.2 \%$ of the variance in TRL was accounted for by PRE, while that due to variation in SIZ was $5.8 \%$, and both of these components were significant $(\mathrm{F}(2,287) \geq 10.2, \mathrm{p}<0.002)$. Dummy size was, thus, about twice as important as prior motivation in determining the level of aggression displayed to the dummy fish.

Because TRL reflects an immediate response to SIZ, it can be argued that the relationship between these two variables should capture virtually all of the effect of dummy size in the experiment. It should not be surprising, therefore, that SIZ showed no additional, independent influence on POST. By this reasoning, the effect of dummy size on post- stimulus motivation is best evaluated in terms of both the unique effect of SIZ and the joint effect of SIZ and TRL on POST. This is the proportion of variance due to SIZ in a regression model that excludes TRL: POST $=\mathrm{p}_{01}$ * $\mathrm{SIZ}+\mathrm{p}_{02}$ * PRE $+\mathrm{B}$.

The effect of SIZ in this model was evaluated first on the data set of 290 "effective" trials, those in which a distinctive response to the dummy was noted (TRL > 0). The analysis was then repeated on the 70 "ineffective" trials, those in which the subject produced no behavior during stimulus presentation $(\mathrm{TRL}=0)$. For the effective trials, the proportion of the variance in POST accounted for by SIZ was $0.5 \%(F(2,287)=1.88, p>$ $0.15)$, insignificantly greater than that observed earlier when the common variance due to TRL had been removed. In the ineffective trials, however, SIZ showed a significant effect on POST, accounting for $5.7 \%$ of the variance $(\mathrm{F}(2,67)=5.50, \mathrm{p}<0.03)$. 


\section{Discussion}

The results are fully consistent with the effects of Behavioral Efference. The level of aggression displayed during presentation of a dummy stimulus had a much larger impact on subsequent aggressive motivation than did the size of the stimulus itself. In fact, the primary effect of stimulus magnitude on post-stimulus motivation was through its influence on the level of aggression displayed during a trial. This strong relationship between performance and post-stimulus motivation, even when prior motivation was controlled for, is exactly what would be predicted by the Behavioral Efference hypothesis.

There was some additional evidence of a direct stimulus effect on motivation, but it was only manifested in those trials in which the subject made no overt response to the dummy. One could infer that the direct effect of the stimulus is relatively weak and is easily overridden by efference from the subject's aggressive displays. Significant direct effects may, therefore, be observable only in cases in which the stimulus configuration does not elicit an overt response. This may provide an explanation for the contrasting results obtained by Heiligenberg (1965) and LEONG (1969), who observed significant direct effects of stimulus configuration on aggressive motivation in two other species of cichlid. In both studies, the subject fish were reported to orient to the dummy stimulus, but not to display any overt aggressive behavior.

\section{Alternative hypotheses}

The greatest problem in interpreting correlational studies is that there is always a possibility that an apparent causal relationship between two variables - in this case, aggression toward the dummy (TRL) and poststimulus motivation (POST) - is actually due to correlated influences on both variables from some additional factor that has not been included in the model. It is, therefore, necessary to consider carefully any such confounding factors and, where it is possible, to evaluate their influence.

The first potential confound is the state of attention of the subject. If the subject is not oriented toward the stimulus apparatus during the interval in which the dummy is presented, it will not respond aggressively. At the same time, its motivational level will remain unaffected, because it will not have been exposed to the stimulus. As a result, a spurious association will be generated between TRL and POST, even in the absence of Behavioral Efference. This possible confound was addressed by re- 
stricting the analysis to just those trials in which a clear response to the dummy was demonstrated. Since a strong effect of TRL on POST was apparent even in this reduced data set, it appears that inattention cannot account for the results.

A second alternative explanation is suggested by the influence of habituation. The subject fish habituated rapidly to the stimulus dummies, in that the magnitude of their aggressive response declined precipitously by the third day of the experiment (Figure 3). It seems reasonable to assume that if habituation rendered the dummies less effective as stimuli for immediate aggressive responding, they would also be less effective in increasing aggressive motivation. Hence, habituation to the stimuli could generate a spurious association between TRL and POST. When the data were reanalyzed after explicitly removing any effects of habituation, however, there was no significant change in the results. Habituation does not appear to be a viable alternative.

A third possibility is that the association is due to some unmeasured perceptual influence. Perhaps both the immediate aggressive display and the subsequent motivational enhancement are tied, not to the actual size of the stimulus dummy, but to its apparent size at the time of presentation. And the apparent size may vary. It could be influenced, for example, by the size of the dummy in the previous trial, or it may vary with the position of the subject in the tank. There appears to be no evidence to support these hypothesis, either. An analysis of the size of the dummy that was presented in the previous trial showed it to have no significant effect on POST and no impact on the relationship between TRL and POST. And although the position of the subject at the time of stimulus presentation was not systematically recorded, the subjects generally responded to the dummy by an immediate, rapid approach to within a few centimeters of the tank wall (Rogers, personal communication). Under these circumstances, judgment of dummy size ought to have been relatively reliable.

Other perceptual accounts of the results can also be developed, if one is willing to postulate the existence of additional, unmeasured cognitive variables. For example, one reader of an earlier version of this paper offered the interpretation that the level of aggression displayed toward the dummy was an indication of the "responsiveness" of the subject, its susceptibility to aggressive stimulation. And if more responsive individuals not merely display more intensively, but also show a greater increment in aggressive motivation from the direct influence of the dummy stimulus, then TRL and POST would be strongly correlated, even in the absence of Behavioral Efference. 
The only operational measure of aggressive motivation is in terms of "attack readiness" (Heiligenberg, 1965; 1976), that is, the ease with which aggressive behavior can be elicited. It is, therefore, hard to imagine how one might quantify "responsiveness" in a manner that was fully independent of aggressive motivation. It even seems odd to consider the possibility that a highly aggressive individual might somehow be unresponsive to appropriate eliciting stimuli.

These misgivings aside, however, "responsiveness," or any other similar perceptual variable, seems unable to account for the central finding in this study: the absence of a correlation between stimulus size and poststimulus motivation when the subject responded to the stimulus and the presence of a significant correlation when the subject did not respond. If the behavior during the stimulus trial was only an indication of "responsiveness," why was the effect of stimulus size not carried through to the post-stimulus interval? If subjects that did not display to the dummy were "unresponsive," why did they show a significant impact of stimulus size on subsequent motivation? It appears that the simplest coherent explanation for this finding has to be that the performance of the behavior itself interfered with the direct motivational effect of the dummy stimulus. And this is precisely what one would expect under the Behavioral Efference hypothesis.

\section{Adaptive significance of Behavioral Efference}

To fully address Maynard Smith's (1984) concerns, it is not enough to show that Behavioral Efference exists. We must also provide a rationale for its existence, an argument to show that efference has an adaptive significance that would outweigh the presumed selective value of deceptive communication. There are several possible candidates. McFarland (1974), for example, has contended that positive feedback from the performance of a behavior is necessary to prevent motivational "dither," in which an animal oscillates ineffectually between two conflicting activities. On a longer time-course, it has recently been shown that aggressive interactions in fish can produce major changes in the structure of the nervous system, changes that mediate the animal's subsequent reproductive maturation (Fraley \& Fernald, 1982; Davis \& Fernald, 1990). It is not clear from these studies that performance of aggressive behavior, as such, brings about these neural modifications, but efference from aggressive displays seems a logical basis for a process of developmental modification. 
I have speculated (Bond, 1989) that Behavioral Efference could play a substantial role in regulating the intensity of an aggressive interaction. In this view, combat is expensive and potentially dangerous, both to oneself and to one's mates and progeny. Its incidence is, therefore, carefully regulated by requiring that a specific, threshold level of aggressive motivation be attained before one animal will attack another. Between aggressive encounters, arousal is maintained at some moderate level that reduces the likelihood of precipitate and unnecessary attacks.

Once a fight begins, however, there is a need for a mechanism that will yield a rapid rise in arousal, to counter the possibility of an attack by the opponent. This is what I suggest to be the principal function of Behavioral Efference: the performance of an aggressive display serves to prepare the displaying animal for combat, increasing its aggressive motivation and readiness to attack. As a consequence, displays coincidentally serve as signals that the likelihood of attack is increasing. The importance of preparation, of overcoming the regulatory inertia that prevents aggressive volatility, is primary, however. It increases the likelihood of winning the encounter through a faster rise to an attack potential (Barlow et al., 1986). At the same time, the need for preparation postpones the moment of attack, allowing other factors to assert themselves and other means of conflict resolution to take effect. The result is a graded or staged arousal process that insures a rapid response to a potential threat, while allowing most conflicts to be resolved by less extreme and risky methods.

Contrary to Hazlett's (1990) concern, however, this argument does not necessarily relegate communication to a peripheral role in the evolution of aggressive display. The hypothesis simply implies that the force of selection in aggressive communication may have principally focused on the receiver of information. If displays are physiologically linked to the underlying level of aggressive motivation, they will be valuable indicators of what an opponent is prepared to do, and there will have been strong selection for the ability to perceive and respond to the cues that they provide. In Krebs \& Dawkins' (1984) terminology, complex, graded aggressive displays represent a dominance of selection for "mind-reading" over that for "manipulation." As long as we do not assume that the essential truthfulness of the "message" carried by a display (Smith, 1977) was the primary selective factor in its evolutionary origin, nothing in Behavioral Efference contradicts traditional ethological accounts of animal communication. 


\section{References}

Baenninger, R. (1974). Some consequences of aggressive behavior: a selective review of the literature on other animals. Aggressive Behavior 1, p. 17-37.

Barlow, G. W. \& Ballin, P. J. (1976). Predicting and assessing dominance from size and colouration in the polychromatic Midas cichlid. Anim. Behav. 24, p. 793-813.

Barlow, G. W., Rogers, W. \& Bond, A. B. (1984). Dummy-elicited aggressive behavior in the polychromatic Midas cichlid. Biol. Behav. 9, p. 115-130.

Barlow, G. W. \& Fraley, N. (1986). Do Midas cichlids win through prowess or daring? It depends. Behav. Ecol. Sociobiol. 19, p. 1-8.

Bond, A. B. (1989). Toward a resolution of the paradox of aggressive displays: II. Behavioral efference and the communication of intentions. Ethology 81, p. 235-249.

Bond, A. B. , Barlow, G. W. \& Rogers, W. (1985). Two modal action patterns with a continuous temporal distribution. Ethology 68, p. 326-334.

Collier, G. (1985). Emotional expression. Erlbaum Associates, Hillsdale, NJ.

Darwin, C. (1872). The expression of the emotions in man and animals. John Murray, London.

Davis, M. R. \& Fernald, R. D. (1990). Social control of neuronal soma size. J. Neurobiology 21, p. 1180-1188.

Dawkins, R. \& Krebs, J. R. (1978). Animal signals: information or manipulation? In: Behavioural ecology, J. R. Krebs \& N. B. Davies, eds.). Blackwell, Oxford, p. 282-309.

Ekman, P., Levenson, R. W. \& Friesen, W. V. (1983). Autonomic nervous system activity distinguishes among emotions. Science 221, p. 1208-1210.

Fraley, N. B. \& Fernald, R. D. (1982). Social control of developmental rate in the African cichlid, Haplochromis burtoni. Z. Tierpsychol. 60, p. 66-82.

Gauch, H. G. (1982). Multivariate analysis in community ecology. Cambridge Univ. Press, Cambridge.

Gauch, H. G. , Whittaker, R. H. \& Wentworth, T. R. (1977). A comparative study of reciprocal averaging and other ordination techniques. J. of Ecology 65, p. 157-174.

Hazlett, B. A. (1990). Evaluation of behavioural efference. Anim. Behav. 40, p. 999-1001.

Heiligenberg, W. (1965). The effect of external stimuli on the attack readiness of a cichlid fish. Z. vergl. Physiol. 49, p. 459-464.

Heiligenberg, W. (1976). A probabilistic approach to the motivation of behavior. In: Simpler networks and behavior (J. Fentress, ed.). Sinauer Associates, Sunderland, MA., p. 301-314.

Hill, M. O. \& Gauch, H. G. (1980). Detrended correspondence analysis, an improved ordination technique. Vegetatio 42, p. 47-58.

Hinde, R. A. (1958). Alternative motor patterns in chaffinch song. Anim. Behav. 6, p. 211-218. (1970). Animal behaviour: a synthesis of ethology and comparative psychology. McGraw-Hill, New York.

Hogan, J. A. \& Bols, R. J. (1980). Priming of aggressive motivation in Betta splendens. Anim. Behav. 28, p. 135-142.

Hogan, J. A. \& Roper, T. J. (1978). A comparison of the properties of different reinforcers. Adv. Study Behav. 8, p. 155-255.

Huntingford, F. A. \& Turner, A. (1987). Animal conflict. Chapman and Hall, London. 
James, L. R., Mulaik, S. A. \& Brett, J. M. (1982). Causal analysis: assumptions, models and data. Sage Publications, Beverly Hills, CA.

Krebs, J. R. \& Dawkins, R. (1984). Animal signals: mind-reading and manipulation. In: Behavioural ecology, 2nd Ed., (J. R. Krebs \& N. B. Davies, eds.). Sinauer Associates, Sunderland, MA, p. 380-402.

Laird, J. D. (1984). The real role of facial response in the experience of emotion: a reply to Tourangeau and Ellsworth, and others. J. Pers. and Soc. Psych. 47, p. 909-917.

Leong, C.-Y. (1969). The quantitative effect of releasers on the attack readiness of the fish Haplochromis burtoni (Cichlidae, Pisces). Z. vergl. Physiol. 65, p. 29-50.

Lorenz, K. (1950). The comparative method in studying innate behaviour patterns. Symp. Soc. Exp. Biol. 4, p. 221-268.

Lorenz, K. (1966). On aggression. Methuen, London. Losey, G. S., Jr. (1982). Intra- and interspecific aggression by the Central American Midas cichlid fish, Cichlasoma citrinellum. Behaviour 79, p. 39-80.

McFarland, D. J. (1971). Feedback mechanisms in animal behaviour. Academic Press, New York.

McFarland, D. J. (1974). Experimental investigation of motivational state. In: Motivational control systems analysis, (D. J. McFarland, ed.). Academic Press, New York, p. 251-282.

Maynard Smith, J. (1984). Game theory and the evolution of behavior. Behav. Brain Sci. 7, p. 95- 101.

Morris, D. (1956). The function and causation of courtship ceremonies. Fondation Singer-Polignac, Colloque Internationale sur L'Instinct, June 1954.

Nelson, K. (1964). The temporal patterning of courtship behaviour in the glandulocaudine fishes (Ostariaphysi, Characidae). Behaviour 24, p. 90-146.

Potegal, M. (1979). The reinforcing value of several types of aggressive behavior: A review. Aggr. Behav. 5, p. 353-373.

Quanty, M. (1976). Aggression catharsis. In: Perspectives on aggression (R. G. Geen \& E. C. O'Neal, eds.). Academic Press, New York, p. 99-132.

SAS Institute (1988). SAS/STAT user's guide. Release 6.03 ed. SAS Inst., Cary, SC.

Smith, W. J. (1977). The behavior of communicating: an ethological approach. Harvard Univ. Press, Cambridge, MA.

Tabachnick, B. G. \& Fidell, L. S. (1983). Using multivariate statistics. Harper and Row, New York.

Tinbergen, N. (1959). Comparative studies of the behaviour of gulls (Laridae): a progress report. Behaviour 15, p. 1-70.

Vodegel, N. (1978). A study of the underlying motivation of some communication behaviors of Pseudotropheus zebra (Pisces, Cichlidae): a mathematical model 1. Proc. Koninklijke Nederl. Akad. van Wetenschappen Amsterdam, Series C 81, p. 211-240.

Wilz, K. J. (1970). Causal and functional analysis of dorsal pricking and nest activity in the courtship of the three-spined stickleback Gasterosteus aculeatus. Anim. Behav. 18, p. 115-124.

Zajonc, R. B. (1985). Emotion and facial efference: a theory reclaimed. Science 228, p. $15-21$. 